\title{
The Components of Metabolic Syndrome in Young Adults
}

\author{
Fabiola MS Adam ${ }^{1}$, John MF Adam ${ }^{2}$, Nang Ei Ei ${ }^{3}$, Tai ES ${ }^{4}$ \\ ${ }^{1,2}$ Division of Endocrinology and Metabolism, Departement of Internal Medicine Faculty of Medicine Hasanuddin University Makassar, \\ Indonesia
}

${ }^{3}$ Saw Swee Hock of Public Health, National University of Singapore

${ }^{4}$ Department of Endocrinology National University of Singapore

\begin{abstract}
Background: Lifestyle changing increased the prevalence of metabolic syndrome. Aim of the study is to find out the prevalence of the components of metabolic syndrome among young adults. Methods: This is a cross sectional study of young adults age 15 - $\leq 39$. AHA/NHLBI criteria was used for the diagnosis of metabolic syndrome. Waist circumference male $\geq 90 \mathrm{~cm}$, female $\geq 80 \mathrm{~cm}$. High triglycerides $\geq 150 \mathrm{mg} / \mathrm{dL}$, low HDL-cholesterol male $<40 \mathrm{mg} / \mathrm{dL}$ and female $<50 \mathrm{mg} / \mathrm{dL}$, elevated blood pressure $\geq 130 / 85$ $\mathrm{mmHg}$, and elevated fasting glucose $\geq 100 \mathrm{mg} / \mathrm{dL}$. Metabolic syndrome, if $\geq 3$ of the categorical cut points. Blood was taken in the morning after 12-hours fasting. Results: In this study, 967 young adults subjects $900 p$ can be covered. No significant difference in age group between females and males i.e $31,45 \pm 6.08$ and $31.73 \pm 6.04$ years $(p=0.0544)$. Central obesity was the highest component, 436 subjects (45.1\%) followed by low HDL-cholesterols 352 (36.4\%), elevated blood pressure 285 (29,5\%), elevated triglycerides 276 (28,5\%), and elevated fasting glucose only 75 individuals (7,8\%). Central obesity, and low HDL cholesterol were significantly higher in females compared to males $50,5 \%$ vs $26,9 \%(p=0,001)$, and $40.1 \%$ vs $24.2 \%(p=0.001)$. Among males, elevated triglycerides and elevated fasting glucose were higher compared to females, $39.5 \%$ vs $25.3 \%(p=0.001)$ and $11.7 \mathrm{vs} 7.8 \%(p=0.013)$. No significant difference in elevated blood pressure $(p=0.059)$. Conclusions: Central obesity was the most prominent component of metabolic syndrome, followed by low HDL-cholesterol and elevated blood pressure, especially among females.
\end{abstract}

Keywords: Metabolic syndrome, components, young adults

\section{Introduction}

Metabolic syndrome is defined as a clustering of metabolic abnormalities that has been found to be associated with risk of coronary heart disease, stroke, and cardiovascular mortality greater than that of its individual components. ${ }^{1}$ In the last two decades, change of lifestyle including increase caloric consumption and less physical activity increased the prevalence of obesity worldwide. ${ }^{2}$ In developing countries such as in Asia-Pacific regions, the prevalence of obesity increases by $2 \%$ per year. ${ }^{2,3}$ As a consequence of rising in obesity, several cardiovascular risk factors are also increasing, followed by increasing the metabolic syndrome. $^{4,5}$.

Since the lack of unifying criteria, the prevalence as well as the components of metabolic syndrome difference between studies. ${ }^{1,6,7}$ In 2001, the National Cholesterol Education Program Expert Panel on Detection, Evaluation, and Treatment of High Blood Cholesterol in Adults (NCEP ATP III) defined a new clinical definition for the diagnosis of metabolic syndrome. ${ }^{8}$ This criteria was designed to be more amenable for the measurement of this syndrome in clinical practice, Later in 2007, a revision of this clinical criteria was introduced by The American Heart Association/National Heart, Lung, and Blood Institute (AHA/NHLDI). ${ }^{7}$ Following the Asian criteria of central obesity, most of the Asian countries used central obesity for male $\geq 90 \mathrm{~cm}$ and female $\geq 80 \mathrm{~cm}^{9}$

Elderly subjects may have different prevalence of metabolic syndrome as well as the components, compared to the younger individuals. Very limited population based study of metabolic syndrome were published in Indonesian Medical Journal, especially among young adults. The purpose of this study is to report the prevalence of metabolic components among young adult individuals in a sub-urban population of Makassar.

\section{Methods}

Subjects in this study were part of the population based study of LIFEcourse study in CARdiovascular disease Epidemiology (LIFECARE). The study was performed from 2009-2011, in the sub-urban population Kecamatan Rappocini of Makassar, which consist of 10 kelurahan. Total population of adults in this area were 150,627 subjects, and the target of the screening was to cover $10 \%$ of each kelurahan. In this population based study for collecting data we used the WHO step wise. The first step, demographic data by interviewing the studied subjects. The second step, physical examination data such as anthropometric measurement (weight, height and waist circumference) and blood pressure. Waist circumference was measured horizontally in the middle between the last arcus costae and anterior spina iliaca in the medial axillaris line (in centimeter unit). The blood pressure was measured three times in sitting position using standard mercury sphygmomanometer. The average of the three measurement was defined as the blood pressure of the subjects. The third step is performing laboratory examination including fasting plasma glucose and lipid profiles i.e. total cholesterol, LDL cholesterol, HDL cholesterol, and triglycerides. All blood samples were taken after 12-hour fasting, and examined in the Central Prodia Laboratory Makassar. 


\section{International Journal of Science and Research (IJSR) \\ ISSN (Online): 2319-7064 \\ Index Copernicus Value (2013): 6.14 | Impact Factor (2014): 5.611}

The criteria of young adults in this study was age between 15 - $\leq 39$ years old, both males and females. For the diagnosis of metabolic syndrome, we used the AHA/NHLBI criteria with the modification of waist circumference followed the Asian criteria. The AHA/NHLBI components of Metabolic syndrome are as followed: central obesity waist circumference $\geq 90 \mathrm{~cm}$ for male and $\geq 80 \mathrm{~cm}$ female, high triglyceride levels $\geq 150 \mathrm{mg} / \mathrm{dL}$ or those on drug treatment for elevated triglycerides, low HDL-cholesterol $<40 \mathrm{mg} / \mathrm{dl}$ for males and $<50 \mathrm{mg} / \mathrm{dl}$ for females or on medication for increasing HDL-cholesterol, elevated blood pressure systolic $\geq 130 / \geq 85 \mathrm{mmHg}$ or those on treatment anti-hypertension drug, and elevated fasting plasma glucose $\geq 100 \mathrm{mg} / \mathrm{dl}$ or thoseon medication for elevated glucose. Diagnosis of metabolic syndrome, if three or more of the above mentioned categorical cut points.

Statistical analysis was conducted using Statistical Package for the Social Sciences (SPSS) for Windows 22.0 (SPSS Inc. Illinois, Chicago) with significant statistical $p$ value of $<$ 0,05 . Comparison of the prevalence of metabolic syndrome between subgroup populations were performed using Pearson Chi-Square, The results were shown in tables and figures.

\section{Results}

\section{Prevalence of Metabolic Syndrome}

In this study, 165 young adult's subjects fulfill the criteria of metabolic syndrome, or a prevalence of $17.1 \%$. Totally females were more common compared to males, 130 in females $(17.5 \%)$ and 35 males $(15.7 \%)$, but the difference was not statistical different $(n=0$ 526) There vx/ac alen nn statistical dif

females and subsequently (

\section{Prevalence of the Components}

During the study, 3502 subjects can be covered, more females than males, 2549 and 953 subsequently. There were 967 young adults in this study, 744 females and 223 males. There was no significant statistically difference in age group between females and males i.e $31,45 \pm 6.08$ years and $31.73 \pm 6.04$ years $(\mathrm{p}=0.0544)$. Among the 967 young adults, central obesity was the highest component, 436 subjects (45.1\%) followed by low HDL-cholesterols 352 (36.4\%), elevated blood pressure $285(29,5 \%)$, elevated triglycerides $276(28,5 \%)$, and elevated fasting plasma glucose being the lowest one only 75 individuals $(7,8 \%)$. Central obesity, and low HDL cholesterol were significantly higher in females compared to males $50,5 \%$ vs $26,9 \%(\mathrm{p}=0,001)$, and $40.1 \%$ vs $24.2 \%(p=0.001)$. Among males, elevated triglycerides and hyperglycemia were higher compared to females, $39.5 \%$ vs $25.3 \% \quad(p=0.001)$ and $11.7 \quad$ vs $7.8 \% \quad(p=0.013)$ subsequently. There was no significant difference in elevated blood pressure $(\mathrm{p}=0.059)$. (table 1$)$

Table 1: The prevalence of metabolic components among 967 young adults

\begin{tabular}{|c|c|c|c|c|c|c|c|}
\hline \multirow{2}{*}{ Component } & \multicolumn{2}{|c|}{$\begin{array}{c}\text { Male } \\
(\mathrm{n}=223)\end{array}$} & \multicolumn{2}{c|}{$\begin{array}{c}\text { Female } \\
(\mathrm{n}=744)\end{array}$} & \multicolumn{2}{c|}{$\begin{array}{c}\text { Total } \\
(\mathrm{n}=967)\end{array}$} & \multirow{2}{*}{$\mathrm{P}^{1)}$} \\
\cline { 2 - 7 } & $\mathrm{n}$ & $\%$ & $\mathrm{n}$ & $\%$ & $\mathrm{n}$ & $\%$ & \\
\hline Obesity & 60 & 26,9 & 376 & 50,5 & 436 & 45,1 & 0.000 \\
\hline Low HDL & 54 & 24,2 & 298 & 40,1 & 352 & 36,4 & 0.000 \\
\hline Elevated BP & 77 & 34,5 & 208 & 28,0 & 285 & 29,5 & 0.059 \\
\hline Elevated TG & 88 & 39,5 & 188 & 25,3 & 26 & 2,7 & 0.000 \\
\hline Hyperglycemia & 26 & 11,7 & 49 & 6,6 & 75 & 7,8 & 0.013 \\
\hline
\end{tabular}

$\mathrm{BP}=$ blood pressure, $\mathrm{TG}=$ triglycerides

${ }^{1)}$ Pearson's Chi-Square test

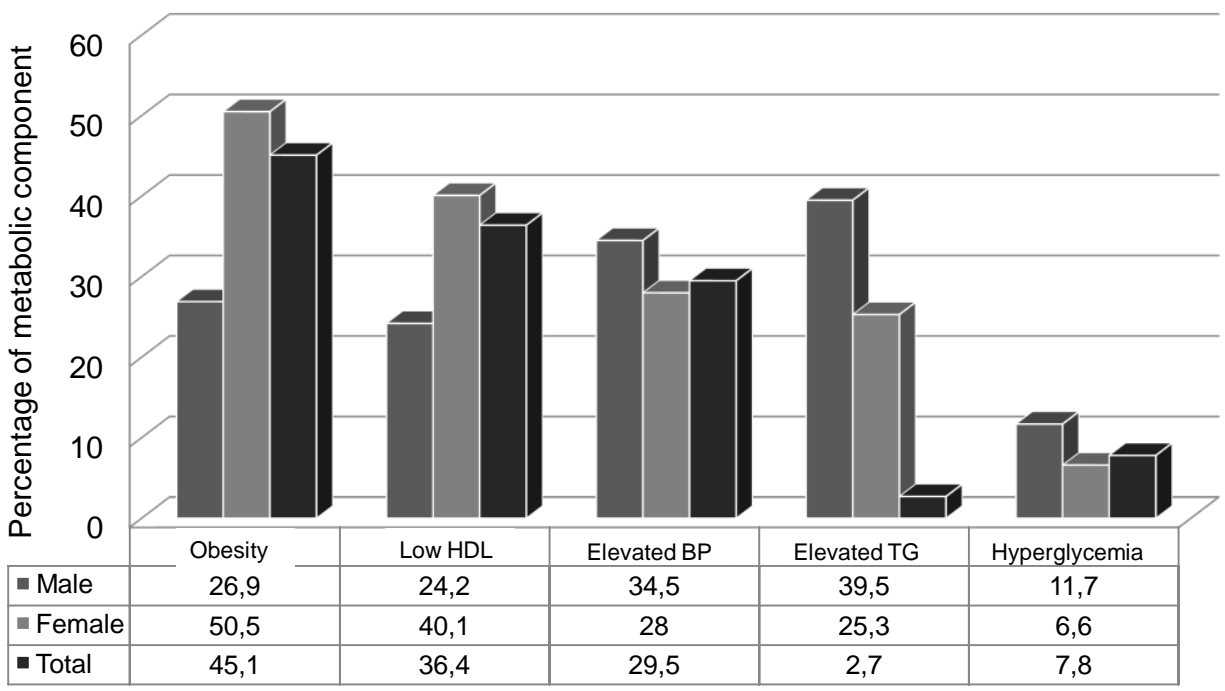

Figure 1: The prevalence of metabolic components

The prevalence of the components according to age trend Following grading to age groups, only central obesity, elevated blood pressure, and elevated triglycerides increased significantly with the increasing of age, the highest being in the age group of 35-39 years. The other two components, low HDL cholesterol and hyperglycemia did not significantly increased, even though the prevalence of these two components were higher among the age group of 35-39 years old. (table 2). 


\section{International Journal of Science and Research (IJSR) \\ ISSN (Online): 2319-7064}

Index Copernicus Value (2013): 6.14 | Impact Factor (2014): 5.611

Table 2: The prevalence of metabolic components among according to age trend

\begin{tabular}{|c|c|c|c|c|c|c|c|c|c|c|c|}
\hline \multirow{4}{*}{ Risk Factor } & \multicolumn{10}{|c|}{ Age } & \multirow{4}{*}{$\mathrm{p}^{1)}$} \\
\hline & \multirow{2}{*}{\multicolumn{2}{|c|}{$\begin{array}{c}15-19 \\
(n=39)\end{array}$}} & \multirow{2}{*}{\multicolumn{2}{|c|}{$\begin{array}{c}20-24 \\
(n=118)\end{array}$}} & \multirow{2}{*}{\multicolumn{2}{|c|}{$\begin{array}{c}25-29 \\
(n=157)\end{array}$}} & \multirow{2}{*}{\multicolumn{2}{|c|}{$\begin{array}{c}30-34 \\
(n=261)\end{array}$}} & \multirow{2}{*}{\multicolumn{2}{|c|}{$\begin{array}{c}35-39 \\
(n=392)\end{array}$}} & \\
\hline & & & & & & & & & & & \\
\hline & $\mathrm{N}$ & $\%$ & $\mathrm{n}$ & $\%$ & $\mathrm{n}$ & $\%$ & $\mathrm{~N}$ & $\%$ & $\mathrm{n}$ & $\%$ & \\
\hline Central Obesity & 9 & 23,1 & 38 & 32,2 & 58 & 36,9 & 109 & 41,8 & 222 & 56,6 & 0,000 \\
\hline Elevated BP & 9 & 23,1 & 31 & 26,3 & 35 & 22,3 & 75 & 28,7 & 135 & 34,4 & 0,041 \\
\hline Low HDL-C & 10 & 25,6 & 40 & 33,9 & 51 & 32,5 & 90 & 34,5 & 161 & 41,1 & 0,115 \\
\hline Elevated TG & 3 & 7,7 & 18 & 15,3 & 31 & 19,7 & 52 & 19,9 & 106 & 27 & 0,005 \\
\hline Hyperglycemia & 0 & 0 & 10 & 8,5 & 11 & 7 & 16 & 6,1 & 40 & 10,2 & 0,112 \\
\hline
\end{tabular}

Pearson Chi Square test

Prevalence of the components according to educational status

Educational status was classified into three different groups, high school students, University students, and post graduate. There was no significant different for most of the components among the three groups, except for elevated blood pressure which was higher in University students. Obesity was more common among high school students, but there was no statistically difference between the three groups.

Table 3: The prevalence of metabolic components according to education

\begin{tabular}{|l|c|c|c|c|c|c|c|}
\hline \multirow{2}{*}{ Risk Factor } & \multicolumn{2}{|c|}{ High school student } & \multicolumn{2}{c|}{ University student } & \multicolumn{2}{c|}{ Post graduate } & \multirow{2}{*}{$\mathrm{p}^{1)}$} \\
\cline { 2 - 8 } & $n$ & $\%$ & $n$ & $\%$ & $n$ & $\%$ & \\
\cline { 2 - 8 } & 365 & 45,3 & 63 & 44,4 & 8 & 42,1 & 0,946 \\
\hline Central Obesity & 230 & 28,5 & 53 & 37,3 & 2 & 10,5 & 0,020 \\
\hline Elevated BP & 301 & 37,3 & 47 & 33,1 & 4 & 21,1 & 0,233 \\
\hline Low HDL-C & 170 & 21,1 & 35 & 24,6 & 5 & 26,3 & 0,566 \\
\hline Elevated TG & 61 & 7,6 & 15 & 10,6 & 1 & 5,3 & 0,434 \\
\hline Hyperglycemia & \multicolumn{7}{|c|}{$(n=806)$} \\
\hline
\end{tabular}

${ }^{1)}$ Pearson Chi Square test

\section{Discussion}

Metabolic syndrome is increased in developed and developing countries. $^{10,11,12,13,14,15}$ In Indonesia several studies among adults have been reported. ${ }^{16,17,18}$ This is the first population based study of young adults in Indonesia, which covered 967 subjects. Widjaja et al from Jakarta ${ }^{19}$ studied a very small selected cases among students, which covered only 70 young adult students. In our study we found that metabolic syndrome is common among young adults in Indonesia.

The components of metabolic syndrome depend on several factors such as criteria, age, socio-economic status, educational state, and also difference in ethnicity. Among the components of metabolic syndrome, we find that central obesity is the highest prevalence, followed by hypertension and low HDL cholesterol levels. Ahmad $\mathrm{M}$ et $\mathrm{al}^{20}$ from Pakistan found that low HDL cholesterol was the most prominent of metabolic component and followed by obesity. The same result was also reported by Matson et $\mathrm{al}^{21}$ where low HDL cholesterol was the highest frequency followed by high triglyceride levels and hypertension. Soysal et $\mathrm{al}^{22}$ from Turkey reported different results, hypertriglyceridemia as the highest followed prevalence, follow by low HDL cholesterol and hypertension. This difference might be due to differences in the criteria they used for metabolic syndrome, selected age groups, and also by the amount of screened subjects. The criteria use for the diagnosis of metabolic syndrome is one of the important difference in the prevalence of this syndrome. Matson et $\mathrm{al}^{21}$ compared three different criteria for the diagnosis of metabolic syndrome, IDF, NCEP ATPIII, and EGIR criteria. The highest prevalence was found with IDF criteria, followed by NCEP criteria. The three studies ${ }^{20,21,22}$ used the classical NCEP ATP criteria with abnormal waist circumference for male $>$ $102 \mathrm{~cm}$, and female $>88 \mathrm{~cm}$, while our study used the AHA/NHLBI with different criteria of waist circumference (modified Asian criteria).

The prevalence of metabolic syndrome increased with increasing age. Our study showed that all the metabolic components except for hyperglycemia increase with increasing age especially in the range age of 30-39 years old. Matson et $\mathrm{al}^{21}$ reported the same results except for low HDL-cholesterol. Soysal et $\mathrm{al}^{22}$ in his study of 567 subjects, age range from 20-39 years old which they divided in two groups, 20-29 and 30-39-year-old, reported that all of the metabolic components is significantly higher among the 30 39 years old. The age range for young adults in The Pakistani study was younger compared to our study age between 17- 25 years old, and the total of adolescents subjects is only $193 .^{20}$ This study shows that educational status is not an important role in the metabolic components. Central obesity is still the highest percentage of metabolic component in all three groups.

In conclusion this study proved that metabolic syndrome among young adults in Indonesia is common. In this study, central obesity, low HDL cholesterol and elevated triglycerides, being the highest components. As we all know that these three factors belong to the high risk factors for cardiovascular disease. Early intervention among adolescents is needed for the prevention of cardiovascular disease. Further study, especially follow up study should be done to monitor the impact of these components. 


\section{International Journal of Science and Research (IJSR) \\ ISSN (Online): 2319-7064}

Index Copernicus Value (2013): 6.14 | Impact Factor (2014): 5.611

\section{Conflict of interest}

No potential conflict of interest relevant to this study was reported.

\section{Acknowledgments}

This study was funded by a grant of Pfizer Inc, New York USA. Special thanks to Prof. ES Tai, Head Department of Endocrinology, National University of Singapore, principle Investigator of The LIFECARE study,

\section{References}

[1] Isomaa B, Almgren P, Tuomi T, Forsen B, Lahti K, Nissen M, et al. Cardiovascular morbidity and mortality associated with the metabolic syndrome. Diabetes Care 2001;24:683-689

[2] World Health Organization, International Obesity Task Obesity Task force and International Association for the study of Obesity. The Asia-Pacific Perspective: redefining obesity and its treatment. Sydney: Health Communications Australia Pty Ltd; 2000.

[3] Gortmaker SL, Must A, Perrin JM, Sobol AM, Dietz WH. Social and economic consequences of overweight in adolescence and young adulthood. $\mathrm{N}$ Engl $\mathrm{J}$ Med 1993; 392: 1008-1012.

[4] Ford ES, Giles WH, Mokdad AH. Increasing prevalence of the metabolic syndrome among US adults. Diabetes Care 2004; 29: $2444-2449$.

[5] Duncan GE, Li SM, Zhou X. Prevalence and trends of a metabolic syndrome phenotype among US adolescents, 1999-2000. Diabetes Care 2004; 29: 2483 - 2443.

[6] Ilanne-Parikka P, Eriksson JG, Lindstrom J, et al. Prevalence of metabolic syndrome and its components: findings from a Finnish general population sample and the Diabetes Prevention Study cohort. Diabetes Care 2004; 29: 2135 - 2140.

[7] Grundy SM, Cleeman JI, Daniels SR, Donato KA, Eckel RH, Franklin BA, Gordon DJ, Krauss RM, Savage PJ, Smith SC, Spertus JA, Costa F. Diagnosis and Management of the Metabolic Syndrome. An American Heart Association/National Heart, Lung, and Blood Institute Scientific Statement. Circulation. 2005.

[8] Executive Summary of the Third Report of the National Cholesterol Education Program (NCEP) Expert Panel on Detection, Evaluation, and Treatment of High Blood Cholesterol in Adults (Adult Treatment Panel III). JAMA 2001; 2486-2497.

[9] The Asia-Pacific perspective: Redefining Obesity and its treatment. In: Inoue $\mathrm{S}$, Zimmet $\mathrm{P}$. Health Communications Australia, 2000.

[10] Ford ES, Giles WH, Dietz WH. Prevalence of metabolic syndrome among US Adults. Findings from the Thrid National Health and Nutrition Examination Survey. JAMA 2002; 287 (3): 356-359.

[11]Deerochanawong C. Metabolic syndrome in the Thai population. JAFES. 2005; 23: S15.

[12] Prasad DS, Kabir Z, Dash AK, Das BC. Prevalence and risk factors for metabolic syndrome in Asian Indians: A community study from urban Eastern India. Journal of Cardiovascular Disease Research 2010; 3: 204-211.
[13]Park HS, Oh SW, Cho SI, Choi WH and Kim YS . The metabolic syndrome and associated lifestyle factors among South Korean adults. International Journal of Epidemiology 2004;33:328-336.

[14] Xu WH, Ruan XN, Fu XJ, Zhu QL, Zhang H, Bai Y, Wu HY, Zhou J, Qiu H, Sun Q, Jiang QW, Yang LM, $\mathrm{Gu}$ JJ and Zhao GM. Prevalence of the metabolic syndrome in Pudong New Area of Shanghai using three proposed definitions among Chinese adults. BMC Public Health 2010, 10:246.

[15] Prevalence of metabolic syndrome in populations of Asian origin. Comparison of the IDF definition with the NCEP definition. DECODA Study Group. Diabetes Res Clin Pract. 2007; 76(1): 57-67.

[16] Adam J, Adriansjah H, Adam F. Sindroma metabolik di klinik. Hasil penelitian di Makasar. In: Tjokroprawiro A, et al, eds. Surabaya Metabolic Syndrome Update-1. Surabaya; 2005. p. 250-6.

[17] Adriansjah H, Adam JMF. Sindroma metabolik : pengertian, epidemiologi, dan kriteria diagnosis. In: Obesitas dan Sindroma Metabolik, $1^{\text {st }}$ ed. Adam JMF,ed. Makassar, 2006; 92-100.

[18] Soewondo P, Purnamasari D, Oemardi M, Waspadji S, Soegondo S. Prevalence of Metabolic Syndrome Using NCEP/ATP III Criteria in Jakarta, Indonesia: The Jakarta Primary Non-communicable Disease Risk Factors Surveillance 2006. Indones J Intern Med. 2010;42 (4):199-203.

[19] Widjaja FF, Widjaja IR, Astria Y, Suwita CS, Waspadji S. Metabolic Syndrome and Framingham risk score in obese yaoung adults. Med J Indones. 2013;22:100-106.

[20] Ahmad M, Hassan S, Hafeez F, Jajja A. Prevalence of various components of metabolic syndrome in our younger population. Pak J Physiol. 2011;7 (2):46-49.

[21] Mattsson N, Ro"nnemaa T, Juonala M, Viikari JSA, Raitakari OT. The prevalence of the metabolic syndrome in young adults. The Cardiovascular Risk in Young Finns Study. J Intern Med. 2007;261:159-169.

[22] Soysal A, Demiral Y, Soysal D, Uçku R, Köseoglu M, Aksakoglu G. The prevalence of metabolic syndrome among young adults in Izmir, Turkey. Anadolu Kardiyol Derg. 2005;5:196-201.

[23] Vasan SK, Thomas N, Christoper S, Geethanjali FS, Paul TV, Sanjeevi CB. Anthropometric measurements for the prediction of the metabolic syndrome: a crosssectional study on adolescents and young adults from southern India. BMJ 2011; 26: 2-7. 